\title{
Genetic Diversity of Selected Mangifera Species Revealed by Inter Simple Sequence Repeats Markers
}

\author{
Zulhairil Ariffin, ${ }^{1}$ Muhammad Shafie Md Sah, ${ }^{2}$ Salma Idris, ${ }^{2}$ and Nuradni Hashim ${ }^{1}$ \\ ${ }^{1}$ Agrobiodiversity and Environment Research Centre, Malaysian Agriculture Research and Development Institute (MARDI), \\ Persiaran MARDI-UPM, 43400 Serdang, Selangor Darul Ehsan, Malaysia \\ ${ }^{2}$ Genebank and Seed Centre, Malaysian Agriculture Research and Development Institute (MARDI), Persiaran MARDI-UPM, \\ 43400 Serdang, Selangor Darul Ehsan, Malaysia \\ Correspondence should be addressed to Zulhairil Ariffin; hairi@mardi.gov.my
}

Received 9 April 2015; Accepted 12 July 2015

Academic Editor: Alexandre Sebbenn

Copyright (C) 2015 Zulhairil Ariffin et al. This is an open access article distributed under the Creative Commons Attribution License, which permits unrestricted use, distribution, and reproduction in any medium, provided the original work is properly cited.

ISSR markers were employed to reveal genetic diversity and genetic relatedness among 28 Mangifera accessions collected from Yan (Kedah), Bukit Gantang (Perak), Sibuti (Sarawak), and Papar (Sabah). A total of 198 markers were generated using nine anchored primers and one nonanchored primer. Genetic variation among the 28 accessions of Mangifera species including wild relatives, landraces, and clonal varieties is high, with an average degree of polymorphism of $98 \%$ and mean Shannon index, $H_{0}=7.50$. Analysis on 18 Mangifera indica accessions also showed high degree of polymorphism of $99 \%$ and mean Shannon index, $H_{0}=5.74$. Dice index of genetic similarity ranged from 0.0938 to 0.8046 among the Mangifera species. The dendrogram showed that the Mangifera species were grouped into three main divergent clusters. Cluster 1 comprised 14 accessions from Kedah and Perak. Cluster II and cluster III comprised 14 accessions from Sarawak and Sabah. Meanwhile, the Dice index of genetic similarity for 18 accessions of Mangifera indica ranged from 0.2588 to 0.7742 . The dendrogram also showed the 18 accessions of Mangifera indica were grouped into three main clusters. Cluster I comprised 10 landraces of Mangifera indica from Kedah. Cluster II comprised 7 landraces of Mangifera indica followed by Chokanan to form Cluster III.

\section{Introduction}

The genus Mangifera belongs to the family of Anacardiaceae. Kochummen [1,2] recorded 40 Mangifera species and they are distributed from India and Sri Lanka throughout Malaysia to the Philippines and Papua New Guinea in the east. Bompard [3] have listed Malayan Peninsula, Borneo, and Sumatra as the highest diversity that can be found in distribution area for this species worldwide. Thirty species have been reported to be recorded in Malaysia. Most of the Mangifera species are domesticated and cultivated in garden orchard or home garden [4]. Example are Mangifera indica (mangga), Mangifera caesia (binjai), Mangifera foetida (bacang), and Mangifera odorata (kuini). Mangifera indica (mango) is the only species being cultivated as a commercial crop. However, at intraspecific level, there are many mango cultivars, clones, and landraces found in the home gardens and orchards. Some of the cultivars, clones, and landraces are difficult to identify using morphological characters. Presently, molecular markers based on polymerase chain reaction (PCR) have been widely used. Molecular markers or also known as DNA markers are known for their rapid and widely used to study the genetic diversity, identify redundancies in germplasm collections, test accession stability and integrity, and resolve taxonomic relationships [5]. Molecular markers for assessment of genetic variation in plants have shown many advantages. They are neutral, not related to age and tissue type, and not influenced by the environmental conditions, have feasibility and lower costs, and are more informative than morphological markers [6]. Thus, molecular markers can be considered to be more effective approach compared to morphological markers to identify plant genotypes in a germplasm or fruit trees collection.

Intersimple Sequence Repeats or ISSR have been proven useful for detecting genetic polymorphisms among accessions by generating a large number of markers that target 
TABLE 1: List of Mangifera species.

\begin{tabular}{|c|c|c|c|}
\hline Site & Species & $\begin{array}{l}\text { Local name } \\
\text { (Landrace/cultivar/clone) }\end{array}$ & Name of sample \\
\hline \multirow{12}{*}{ Yan, Kedah } & Mangifera indica $\mathrm{L}$. & Pelam Harumanis & HarumanisY \\
\hline & Mangifera indica $\mathrm{L}$. & Pelam Pedal Ayam & PedalAyam \\
\hline & Mangifera indica L. & Pelam Sala & PelamSala \\
\hline & Mangifera indica $\mathrm{L}$. & Pelam Air & PelamAir \\
\hline & Mangifera indica L. & Mangga Telur & MangTel \\
\hline & Mangifera indica $\mathrm{L}$. & Pelam Ciku & PelamCiku \\
\hline & Mangifera indica $\mathrm{L}$. & Pelam Sawa & PelamSaw \\
\hline & Mangifera indica L. & Pelam Pipi Merah & PelPipMer \\
\hline & Mangifera indica L. & Pelam 6 Kati & P6Kati \\
\hline & Mangifera indica $\mathrm{L}$. & Harumanis & PHarmanis \\
\hline & Mangifera foetida Lour & Bacang & BaclYan \\
\hline & Mangifera foetida Lour & Bacang & Bac2Yan \\
\hline \multirow{2}{*}{ Bukit Gantang, Perak } & Mangifera foetida Lour & Bacang & BacPerak \\
\hline & Mangifera pentandra Hook f. & Mempelam Bemban & MBemban \\
\hline \multirow{7}{*}{ Sibuti, Sarawak } & Mangifera indica $\mathrm{L}$. & Mahathir & MahathirS1 \\
\hline & Mangifera indica $\mathrm{L}$. & Harumanis & HarumanisS \\
\hline & Mangifera indica $\mathrm{L}$. & Chokanan & Chokanans \\
\hline & Mangifera indica $\mathrm{L}$. & Mangga Apel & MangApelS \\
\hline & Mangifera indica L. & Mahathir & MahathirS2 \\
\hline & Mangifera odorata Griff. & Kuini & Kuinis \\
\hline & Mangifera pentandra Hook f. & Mempelam & MempelamS \\
\hline \multirow{7}{*}{ Papar, Sabah } & Mangifera indica $\mathrm{L}$. & Mangga Manila & MangManila \\
\hline & Mangifera indica L. & Mangga Apel & MApelSbh \\
\hline & Mangifera indica L. & Alor Manis & AlorManis \\
\hline & Mangifera laurina Blume & Mangga Air 1 & MangAir1 \\
\hline & Mangifera laurina Blume & Mangga Air 2 & MangAir2 \\
\hline & Mangifera odorata Griff. & Wani & WaniSbh \\
\hline & Mangifera caesia Jack & Belunu Manis & BelunuManis \\
\hline
\end{tabular}

multiple microsatellite loci distributed across the genome. ISSR are often used because of their capability of reproducibility, with no gene sequence information, and prior genetic studies are required for the analysis. ISSR markers have been reported to undertake the assessment of genetic diversity of mango cultivars [7], cashew germplasm [8], and "uba" mango tree in Brazil [9], identification of mango cultivars of Thailand [10], and also the genetic diversity analysis of Asian bitter gourd (Momordica charantia L.) in India [11].

This study was undertaken to assess the genetic diversity and genetic relationship of Mangifera species and cultivars/landraces/clones in four sites using ISSR in order to provide basic information for future biodiversity conservation and management program of the Mangifera genetic resources.

\section{Materials and Methods}

2.1. Plant Materials. Leaf samples of 28 accessions from six Mangifera species were collected from Yan (Kedah), Bukit
Gantang (Perak), Sibuti (Sarawak), and Papar (Sabah) as listed in Table 1.

2.2. DNA Extraction. Total genomic DNA was isolated from Mangifera leaves (2-3 g) using CTAB method as described by Murray and Thompson [12] with slight modifications. The DNA solution was quantified using biospectrophotometer to check the quality and quantity of DNA extracted. DNA samples with ratio absorbance $260 / 280$ of more than 1.8 will be considered good to proceed for the next steps. DNA bands were also checked on $1 \%$ agarose gel electrophoresis. The DNA was then diluted with sterile distilled water into a concentration of $60 \mathrm{ng} / \mu \mathrm{L}$.

2.3. ISSR Analysis. A total of 15 sets of primers were tested for ISSR amplification. The 15 ISSR primers are UBC-808, UBC-809, UBC-811, UBC-826, UBC-834, UBC841, UBC854, UBC-855, UBC-868, UBC-873, UBC-876, UBC-881, UBC-886, UBC-891 and UBC-895. The final volume of PCR reaction was $25 \mu \mathrm{L}$ which contains $2 \mathrm{mM} \mathrm{MgCl}_{2}, 0.2 \mathrm{mM}$ 
TABLE 2: Profiles of ISSR primers used for ISSR analysis.

\begin{tabular}{lcccc}
\hline Number Name of primer & Primer sequence $5^{\prime}-3^{\prime}$ & $\mathrm{Ta}\left({ }^{\circ} \mathrm{C}\right)$ & $\% \mathrm{GC}$ \\
\hline 1 & UBC-808 & $(\mathrm{AG})_{8} \mathrm{C}$ & 54.2 & 52.9 \\
2 & $\mathrm{UBC}-811$ & $(\mathrm{GA})_{8} \mathrm{C}$ & 54.2 & 52.9 \\
3 & $\mathrm{UBC}-826$ & $(\mathrm{AC})_{8} \mathrm{C}$ & 54.0 & 46.7 \\
4 & $\mathrm{UBC}-841$ & $(\mathrm{GA})_{8} \mathrm{YC}$ & 55.0 & 50.0 \\
5 & $\mathrm{UBC}-855$ & $(\mathrm{AC})_{8} \mathrm{YT}$ & 59.0 & 44.4 \\
6 & $\mathrm{UBC}-873$ & $(\mathrm{GACA})_{4}$ & 50.2 & 50.0 \\
7 & $\mathrm{UBC}-876$ & $(\mathrm{GATA})_{2}(\mathrm{GACA})_{2}$ & 45.0 & 37.5 \\
8 & $\mathrm{UBC}-881$ & $\mathrm{GGG}(\mathrm{TGGGG})_{2} \mathrm{TG}$ & 59.0 & 82.4 \\
9 & $\mathrm{UBC}-886$ & $\mathrm{VDV}(\mathrm{CT})_{7}$ & 54.0 & 41.2 \\
10 & $\mathrm{UBC}-891$ & $\mathrm{HVH}(\mathrm{TG})_{7}$ & 54.0 & 41.2 \\
\hline
\end{tabular}

dNTP, $2.5 \mu \mathrm{L}$ buffer $(10 \mathrm{x}), 0.2 \mu \mathrm{L}$ Taq DNA polymerase, $0.2 \mu \mathrm{M}$ primer, and $60 \mathrm{ng}$ DNA template. The thermal profile of the PCR reaction was programmed as follows: initial denaturation at $92^{\circ} \mathrm{C}$ for 1 minute, followed by 40 cycles at $92^{\circ} \mathrm{C}$ for a min, annealing at $50^{\circ} \mathrm{C}-60^{\circ} \mathrm{C}$ for 2 minutes, and extension at $72^{\circ} \mathrm{C}$ for 2 minutes. The final extension was at $72^{\circ} \mathrm{C}$ for 5 minutes followed by cooling to $4^{\circ} \mathrm{C}$. The annealing temperature, $\mathrm{Ta}\left({ }^{\circ} \mathrm{C}\right)$, and \% GC content were given in Table 2. The amplified products were separated on $1.8 \%$ agarose gels with $1 \mathrm{x}$ TAE buffer at $60 \mathrm{~V}$ for 150 minutes. The gels and the bands were visualized and acquired under UV light using GelDoc2000 documentation system. The size of the amplified products was estimated using 2-log DNA bp ladder.

2.4. Data Analysis. Shannon's diversity indices $(H)$ were calculated [13]. Amplified products which appeared reproducible and distinct were scored as present (1) or absent (0). The performance of ISSR markers used was measured using three parameters: polymorphic information content (PIC), marker index (MI), and resolving power (RP). PIC was calculated using the following formula; PIC $i=2 f i(1-f i)$, where PIC $i$ is the polymorphic information content of the locus $i, f i$ is the frequency of the amplified fragments, and (1$f i$ ) is the frequency of nonamplified fragments. The PIC for each primer was calculated using the average PIC value from all loci of each primer $[14,15]$. Marker index was calculated as product of polymorphic information content and effective multiplex ratio; $\mathrm{MI}=\mathrm{EMR} \times \mathrm{PIC}$ [16]. The ability of a primer to differentiate between genotypes or also known as resolving power (RP) was also calculated; $\mathrm{RP}=\sum I b$. Ib represents the informative fragments by the following formula: $I b=$ $1-(2 \times|0.5-p i|)$, where $p i$ is the proportion of the species containing the $i$ th band [17].

The binary data was used for calculating Dice coefficient and a similarity coefficient matrix was constructed. The cluster analysis was used based on the methods of Unweighted Pair-Group Method for Arithmetic Averages Analysis (UPGMA) [18] using computer programme Ntsyspc version 2.11 [19]. Bootstrap analysis was performed using WinBoot [20] software to test the consistency or the statistical significance of the genetic relationships between species shown in the dendrograms.

\section{Results and Discussion}

Out of 15 ISSR primers screened, only ten ISSR primers were chosen. The primers consist of nine anchored primers (dinucleotide, tetranucleotide, and pentanucleotide repeats) named as UBC-808, UBC-811, UBC-826, UBC-841, UBC855, UBC-873, UBC-886, UBC-881, and UBC-891 including one nonanchored primer (tetranucleotide repeats) named as UBC-876. The chosen primers were able to produce polymorphic banding patterns and each primer had different annealing temperatures that ranged from $50.0^{\circ} \mathrm{C}$ to $60.0^{\circ} \mathrm{C}$ (Table 2).

A total of 198 markers were generated with polymorphism in 197 bands (99.4\%). The number of polymorphic markers varied from 11 (UBC-811) to 25 (UBC-855) with an average of 19.7 polymorphic bands per primer. The size of the amplified products ranges from $250 \mathrm{bp}$ to $6000 \mathrm{bp}$ (Table 3). Another set of data also were calculated using only 18 Mangifera indica accessions (Table 4). Of these, a total of 163 polymorphic markers were obtained which showed $98 \%$ polymorphism.

In this study, high PIC value was observed for primer UBC-841 at 0.52 and low PIC value of 0.12 for primer UBC826 , with an average of PIC value per primer 0.27 , was obtained for 28 Mangifera accessions. The highest effective multiplex ratio (EMR) was observed with the primer UBC891 (6.46) and the lowest was observed with the primer UBC876 (2.50), with an average EMR of 4.32 per primer. The highest MI was observed with the primer UBC-891 (2.13) and the lowest in the primer UBC-873 (0.58) with an average MI of 1.19 per primer was obtained. Meanwhile, the highest $\mathrm{RP}$ value was observed with the primer UBC-811 (22.18) and the lowest with the primer UBC-873 (7.0) with an average RP of 12.94 per primer was obtained. On the other hand, PIC value of 0.34 for primer UBC-891 and low PIC value of 0.21 for primer UBC-873, with an average PIC value of 0.27 per primer, were obtained for 18 Mangifera indica accessions. The highest effective multiplex ratio (EMR) was observed with the primer UBC-886 (7.67) and the lowest was observed with the primer UBC-873 (2.67), with an average EMR of 4.49 per primer. The highest MI was observed with the primer UBC-891 (2.34) and the lowest in the primer UBC-873 (0.56) with an average MI of 1.25 per primer was obtained. However, the highest RP value was observed with the primer UBC-811 (18.0) and the lowest with the primer UBC-873 (6.4) with an average RP of 10.33 per primer was obtained. Both ISSR analyses showed that the primers, UBC811 and UBC-891, were considered as good markers based on the high value of MI and RP, respectively. On the contrary, PIC values indicated that the primers used were different for both analyses, UBC-841 for 28 Mangifera accessions and UBC-891 for 18 Mangifera indica accessions. Gajera et al. [21] reported low PIC values that ranged from 0.138 for primer UBC-807 to 0.393 for primer UBC-825 using 21 ISSR primers on 20 Mangifera indica genotypes of Indian Gir forest region. Srivastava et al. [22] also reported PIC value of 0.217 with 12 ISSR markers which was lower compared to RAPD (0.245) and DAMD (0.298) markers systems used but indicated higher value of MI (marker index) which showed the efficiency of ISSR markers. High PIC value may 
TABLE 3: List of 10 ISSR primers used for polymorphism detection on 28 Mangifera accessions.

\begin{tabular}{|c|c|c|c|c|c|c|c|c|}
\hline Primer & $\mathrm{TB}$ & $\mathrm{PB}$ & PPB (\%) & $\begin{array}{l}\text { Amplicon band size } \\
\text { (bp) }\end{array}$ & PIC & EMR & MI & $\mathrm{RP}$ \\
\hline UBC-808 & 18 & 17 & 94.4 & $450-2500$ & 0.23 & 4.12 & 0.95 & 13.56 \\
\hline UBC-811 & 11 & 11 & 100 & $430-2500$ & 0.29 & 4.36 & 1.26 & 22.18 \\
\hline UBC-826 & 25 & 25 & 100 & $500-3200$ & 0.12 & 3.89 & 0.47 & 8.72 \\
\hline UBC-841 & 20 & 20 & 100 & $250-3000$ & 0.52 & 3.93 & 2.04 & 12.5 \\
\hline UBC-855 & 25 & 25 & 100 & $300-6000$ & 0.23 & 4.07 & 0.94 & 9.12 \\
\hline UBC-873 & 20 & 20 & 100 & $900-5000$ & 0.17 & 3.43 & 0.58 & 7.00 \\
\hline UBC-876 & 18 & 18 & 100 & $700-5000$ & 0.25 & 2.50 & 0.63 & 10.67 \\
\hline UBC-881 & 18 & 18 & 100 & $700-5000$ & 0.24 & 3.11 & 0.75 & 9.67 \\
\hline UBC-886 & 21 & 21 & 100 & $350-2800$ & 0.29 & 7.32 & 2.12 & 19.52 \\
\hline UBC-891 & 22 & 22 & 100 & $350-3000$ & 0.33 & 6.46 & 2.13 & 16.45 \\
\hline Total & 198 & 197 & & & & & & \\
\hline Mean & 19.8 & 19.7 & 99.44 & & 0.27 & 4.32 & 1.19 & 12.94 \\
\hline
\end{tabular}

TB: total band, PB: polymorphic band, PPB (\%): percentage of polymorphic band (\%), PIC: polymorphic information content, EMR: effective multiplex ratio, MI: marker index, and RP: resolving power of primer.

TABLE 4: List of 10 ISSR primers used for polymorphism detection on 18 Mangifera indica accessions.

\begin{tabular}{|c|c|c|c|c|c|c|c|c|}
\hline Primer & $\mathrm{TB}$ & $\mathrm{PB}$ & $\mathrm{PPB}(\%)$ & $\begin{array}{l}\text { Amplicon band size } \\
\text { (bp) }\end{array}$ & PIC & EMR & MI & $\mathrm{RP}$ \\
\hline UBC-808 & 13 & 12 & 92.3 & $450-2500$ & 0.29 & 4.21 & 1.22 & 12.62 \\
\hline UBC-811 & 10 & 9 & 90 & $430-2500$ & 0.25 & 4.50 & 1.13 & 18.00 \\
\hline UBC-826 & 19 & 19 & 100 & $500-3200$ & 0.26 & 4.44 & 1.15 & 8.42 \\
\hline UBC-841 & 16 & 16 & 100 & $300-3000$ & 0.28 & 4.11 & 1.15 & 9.25 \\
\hline UBC-855 & 22 & 22 & 100 & $300-6000$ & 0.26 & 4.22 & 1.10 & 6.91 \\
\hline UBC-873 & 15 & 15 & 100 & $900-5000$ & 0.21 & 2.67 & 0.56 & 6.40 \\
\hline UBC-876 & 16 & 16 & 100 & $700-5000$ & 0.25 & 3.22 & 0.81 & 7.25 \\
\hline UBC-881 & 16 & 16 & 100 & $700-5000$ & 0.26 & 3.00 & 0.78 & 6.75 \\
\hline UBC-886 & 18 & 18 & 100 & $350-2800$ & 0.29 & 7.67 & 2.22 & 15.33 \\
\hline UBC-891 & 20 & 20 & 100 & $450-3000$ & 0.34 & 6.89 & 2.34 & 12.40 \\
\hline Total & 165 & 163 & & & & & & \\
\hline Mean & 16.6 & 16.3 & 98.23 & & 0.27 & 4.49 & 1.25 & 10.33 \\
\hline
\end{tabular}

TB: total band, PB: polymorphic band, PPB (\%): percentage of polymorphic band (\%), PIC: polymorphic information content, EMR: effective multiplex ratio, MI: marker index, and RP: resolving power of primer.

be contributed by tetranucleotide repeats GAGA and GACA contained in the primers as discussed by He et al. [23].

3.1. ISSR Analysis Using 28 Mangifera Accessions. The degree of genetic variation among the 28 Mangifera accessions calculated from the data of each primer showed the highest value (Shannon index, $\left.H_{0}: 9.51\right)$ for UBC-886 and the lowest $\left(H_{0}\right.$ : 5.84) for UBC-873. The mean value for $H_{0}$ is 7.50 , indicating a high level of genetic diversity among the 28 Mangifera accessions. The high of Shannon index for 28 Mangifera accessions may be influenced by different cultivation locations where the samples were collected, from Yan (Kedah), Bukit Gantang (Perak), Sibuti (Sarawak), and Papar (Sabah), due to the dynamic agrogeographical conditions, respectively. The different level of species occurring in the 28 Mangifera accessions may also contribute to the higher diversity value.
The genetic relationship of 28 Mangifera accessions was obtained from the markers data using Dice similarity coefficient. Dice's similarity matrix (table not shown) indicated the pairwise comparison of the relative genetic similarity between 28 Mangifera accessions ranging from a maximum of 0.8046 (between Mangga Air 1 and MempelamS) to a minimum of 0.0938 (between Pelam 6 Kati and Belunu Manis). The genetic relatedness of 28 Mangifera accessions was shown in the dendrogram constructed using Dice's similarity coefficient values. The 28 Mangifera accessions were distributed into three main divergent clusters, I, II, and III, at coefficient value of 0.53 (Figure 1).

Cluster I consists of three subclusters (A, B, and C). Subcluster A consists of ten landraces, cultivars, and clones of Mangifera indica originated from Yan, Kedah. They were Harumanis, Pelam Harumanis, Pelam Pedal Ayam, Pelam 


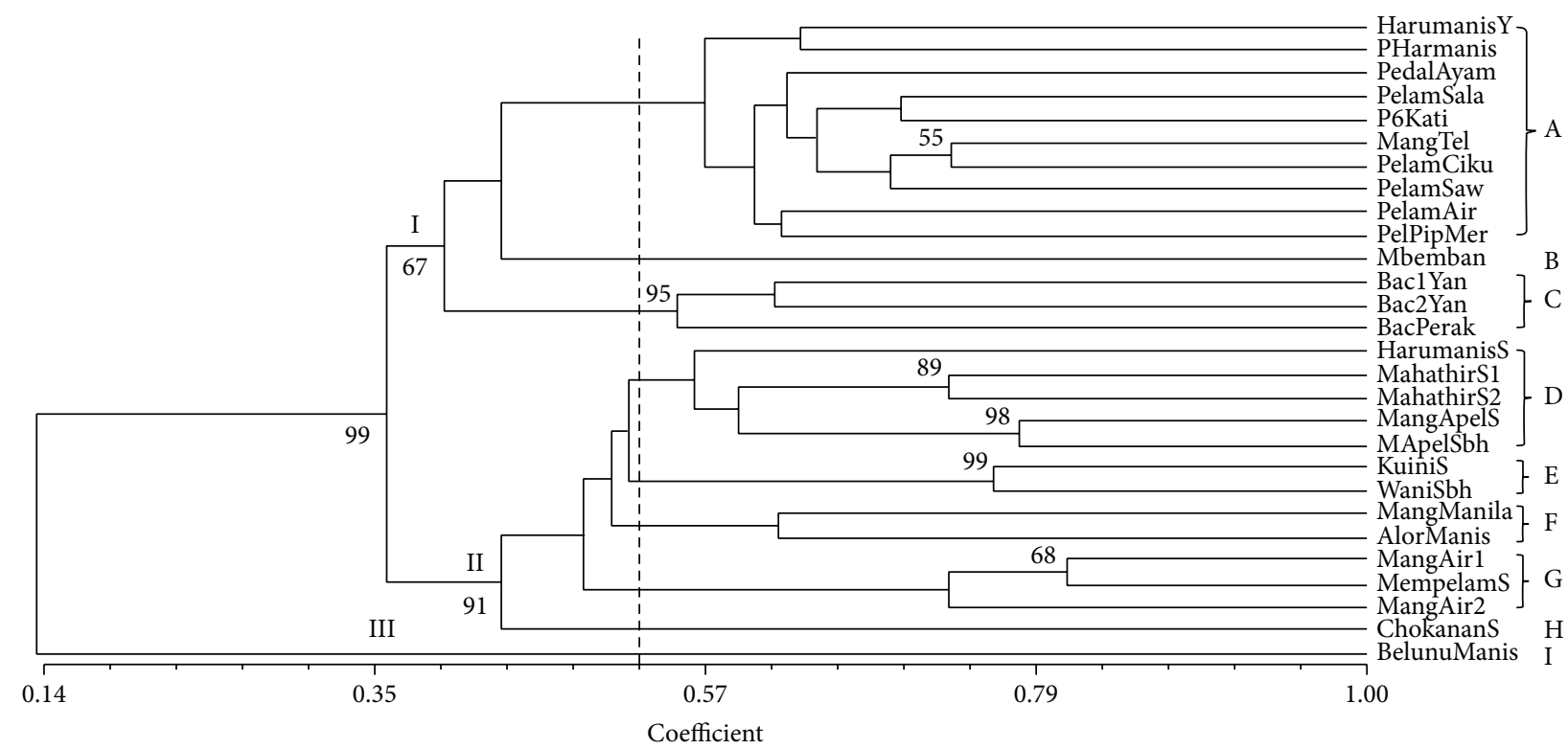

FIGURE 1: Cluster of 28 Mangifera accessions based on Dice similarity coefficient with bootstrap significance values.

Sala, Pelam 6 Kati, Mangga Telur, Pelam Ciku, Pelam Sawa, Pelam Air, and Pelam Pipi Merah. Both Harumanis and Pelam Harumanis were separated from the other landraces due to their clonal type. Only Mangga Telur and Pelam Ciku were found very closely related with a bootstrap significance value of $55 \%$. Subcluster B composed of only one species of Mangifera pentandra named as Mempelam Bemban originated from Bukit Gantang, Perak, while subcluster C consisted of three landraces of Mangifera foetida (bacang) originated from Yan, Kedah, and Bukit Gantang, Perak, with a very high bootstrap significance value of 95\%. Based on the cluster formed, it was clearly shown that different species of Mangifera were distributed into specific clusters, in which subcluster A has all the landraces of Mangifera indica including two clones, while subcluster B has only Mangifera pentandra and subcluster $\mathrm{C}$ has Mangifera foetida.

Cluster II consisted of three subclusters (D, E, F, G, and H) with a total of twelve landraces of Mangifera species including one clone (Harumanis) originated from Sibuti, Sarawak, and Papar, Sabah. Subcluster H consisted of only one clone of Mangifera indica named as Chokanan. While subcluster D consisted of four landraces of Mangifera indica, two landraces named Mahathir, two landraces named Mangga Apel, and one clone, Harumanis. Landraces Mahathir together with Mangga Apel were found very closely related with bootstrap of significance value of $89 \%$ and $98 \%$, respectively. Two wild relatives (Mangifera odorata) named as Kuini and Wani were grouped in subcluster E, having the highest bootstrap significance value of $99 \%$. However, Mangga Manila and Alor Manis were separated from the other Mangifera landraces to form subcluster F. Two wild relatives of Mangifera, named as Mangga Air (Mangifera laurina) and Mempelam (Mangifera pentandra), were grouped in subcluster G. The Mempelam from Sibuti, Sarawak, was found to be closely related to Mangga Air 1 originated from Papar, Sabah, with a bootstrap significance value of $68 \%$. A report also shared similar finding with one accession of Mangifera indica found closely related to a group containing Mangifera odorata accessions. Nevertheless, Yamanaka et al. [24] have succeeded to classify 35 accessions comprising 11 M. indica L., 11 M. odorata Griff., 7 $M$. foetida Lour., and $6 \mathrm{M}$. caesia Jack accessions into 4 groups corresponding to the 4 Mangifera species using AFLP.

Finally, cluster III also known as subcluster I showed only one landrace of Mangifera caesia named as Belunu Manis originated from Papar, Sabah. Belunu Manis showed more divergent relationship from the other groups of Mangifera species. In addition, the morphology characteristics of this species are quite different from the other groups. It can be seen that Mangifera caesia is quite distant from the other species based on the dendrogram generated by AFLP [24]. Obviously, the Mangifera species were divided into two major clusters; one cluster has all the Peninsular of Malaysia's species and the other cluster has eastern of Malaysia's species based on the bootstrap significance value of $67 \%$ and $99 \%$, respectively.

3.2. ISSR Analysis Using 18 Mangifera indica. The degree of genetic variation among the 18 Mangifera indica accessions calculated from the data of each primer showed the highest value (Shannon index, $H_{0}$ : 6.45) for UBC-891 and the lowest $\left(H_{0}: 4.85\right)$ for UBC-873. The mean value for $H_{0}$ is 5.74, indicating a high level of genetic diversity among the Mangifera indica compared to the value of 6.00 for 211 Nephelium lappaceum accessions [25] and 2.32 for 85 Lansium domesticum accessions [26]. The high of Shannon index for 18 Mangifera indica accessions may be influenced by different cultivation locations where the samples were collected, from Yan (Kedah), Sibuti (Sarawak), and Papar (Sabah), due to the dynamic agrogeographical conditions, respectively. 


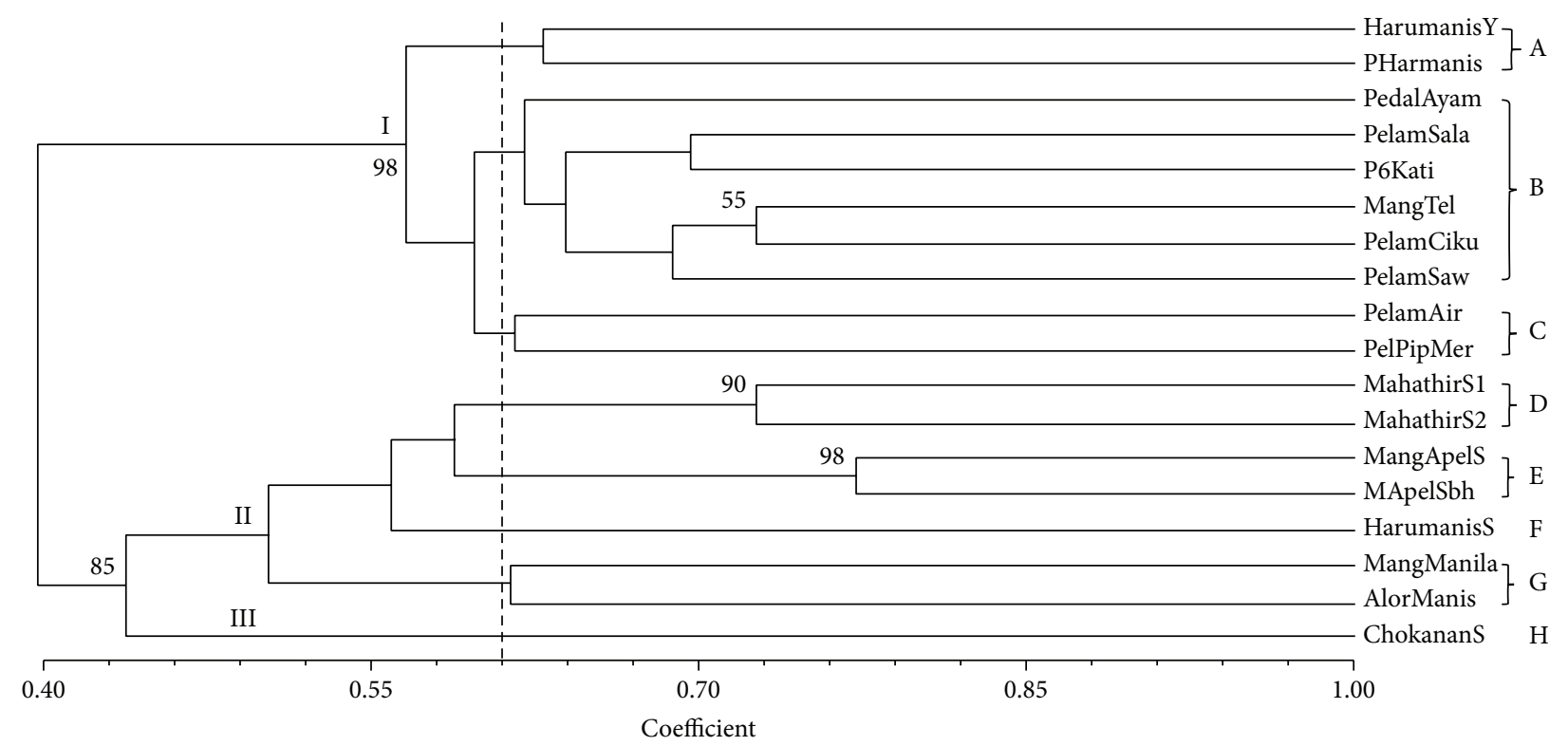

Figure 2: Cluster of 18 accessions (Mangifera indica) based on Dice similarity coefficient with bootstrap significance values.

The genetic relationship of Mangifera indica was obtained from the markers data using Dice similarity coefficient. Dice's similarity matrix (table not shown) indicated the pairwise comparison of the relative genetic similarity between 18 Mangifera indica accessions ranging from a maximum of 0.7742 (between Mangga Apel Sabah and Mangga Apel Sarawak) to a minimum of 0.2588 (between Pelam Pipi Merah and Mangga Manila). The genetic relatedness of Mangifera indica was shown in the dendrogram constructed using Dice's similarity coefficient values.

In comparison to Figure 1, the 18 accessions were distributed into three main divergent clusters, I, II, and III, at coefficient value of 0.61 (Figure 2). Cluster I consisted of three subclusters (A, B, and C). Subcluster A consists of only two accessions named Harumanis and Pelam Harumanis. Subcluster B composed of 6 landraces named Pelam Pedal Ayam, Pelam Sala, Pelam 6 Kati, Mangga Telur, and Pelam Ciku. Mangga Telur and Pelam Ciku were closely related with a bootstrap significance of more than 55\%. Pelam Air and Pelam Pipi Merah were grouped in subcluster C. All accessions in subclusters $\mathrm{A}, \mathrm{B}$, and $\mathrm{C}$ were originated from Yan, Kedah.

Cluster II consisted of four subclusters (D, E, F, and G). Subcluster D was represented by clone Mahathir with a bootstrap significance of $90 \%$. Harumanis originated from Sibuti, Sarawak, was the only clone in subcluster E. However, each of Mangga Apel originated from Sibuti, Sarawak, and Papar, Sabah, together with Mangga Manila and Alor Manis also originated from Papar, Sabah, was grouped in subcluster F and subcluster G, respectively. Mangga Apel was found very closely related with a bootstrap significance of $98 \%$ which was the highest value followed by Mahathir in subcluster D.

Cluster III consisted of one accession named Chokanan, the only clone representing subcluster $\mathrm{H}$. All Mangifera indica in clusters II and III were collected from Sibuti, Sarawak, and Papar, Sabah.

Based on the clustering analysis, it was obvious that the 18 Mangifera indica accessions were divided into 2 major clusters; one cluster has all the Peninsular of Malaysia's accessions and the other cluster has east of Malaysia's accessions based on the bootstrap significance value of $98 \%$ and $85 \%$, respectively.

Many studies were conducted to determine the genetic variation of Mangifera species [27-30]. For Mangifera species, morphological characters such as fruit and leaves characters have been used in the early years to show differences among the accessions. The leaf and fruit characters have been observed to be highly heritable and used to classify the Thai mango [27]. Salma et al. [29] have identified 26 mango clones into four groups based on the flower and fruit characters. The high degree of variation may depend on the methods used. PCR based method has become a very useful tool to aid the classification works more easily. It is also very effective method to improve the management of germplasm collections in terms of duplicate identification, estimation of diversity, and enhancement utilization of the existing collections. Various studies on genetic variation using RAPD, ISSR, SSR, and AFLP on the Mangifera species have been reported [7, 10, 31-35].

The study reveals high value of genetic diversity among the 28 Mangifera accessions. Usually, the fixation of new alleles in specific population along with recombination and segregation of alleles by open-pollination of genetically different in mangoes in varied agroclimates may contribute to the high genetic diversity index [36]. The broad range of Dice similarity matrix for both analyses indicated that the level genetic variability for 28 Mangifera accessions which comprised of landrace/cultivar/clone was influenced 
by the environmental changes that occurred in the four sites. Furthermore, the clustering analysis showed that there were significant dissimilarities among the 28 Mangifera accessions originated from the Peninsular of Malaysia compared to Sarawak and Sabah regions. Karihaloo et al. [34] and Ravishankar et al. [35] reported that there is isolation within mango cultivars between North and South India using RAPD. This is in contrast to a report which stated the otherwise which claimed no separation between the mango cultivars from North India and South India using ISSR [7]. However, in another report, cumulative data using RAPD, ISSR, and DAMD methods have succeeded to cluster the mango cultivars into two different regions of India, eastern and northern regions [22].

The information on genetic diversity and genetic relationship of the Mangifera species is very important to be documented for proper identification of Mangifera species. This knowledge can be used as a tool for plant breeders to improve the strategies in breeding programmes as well as an initial effort to establish the conservation programme of the Mangifera species. Thus, an adequate study of local collections must be conducted before the accessions are lost, especially the wild relatives of Mangifera species. In order to prevent the loss, the farmers should be educated to maintain the valuable materials they possessed in their home garden or orchards. Therefore, consideration should be made to keep these accessions available in the germplasm collections for the future.

\section{Conclusion}

In summary, this study showed that ISSR are useful markers in genetic diversity studies based on the very high polymorphism level detected by the primers in the 28 Mangifera accessions collected. The ISSR markers are also suitable for determining the genetic similarity among the Mangifera species which are able to group them accordingly based on their origins, Peninsular and eastern of Malaysia. It is also recommended that these Mangifera accessions need to be conserved on farm and also collected for germplasm collection for conservation programmes. Perhaps these accessions may become useful as a genetic material in the breeding research in the future, especially the wild relatives of Mangifera species which are capable of developing resistant factors to disease and pest of mango cultivation.

\section{Conflict of Interests}

The authors declare that there is no conflict of interests regarding the publication of this paper.

\section{Acknowledgments}

This study is the output of the UNEP/GEF supported regional project "Conservation and Sustainable Use of Cultivated and Wild Tropical Fruit Diversity: Promoting Sustainable Livelihoods, Food Security, and Ecosystem Services," implemented in India, Indonesia, Malaysia, and Thailand. The project is coordinated regionally by the Bioversity International in collaboration with Indian Council of Agricultural Research (ICAR), New Delhi; Indonesian Centre for Horticulture Research and Development (ICHORD), Jakarta; Malaysian Agricultural Research and Development Institute (MARDI), Kuala Lumpur; and Department of Agriculture (DOA), Bangkok.

\section{References}

[1] K. Kochummen, "Anacardiaceae," in Tree Flora Sabah Sarawak, Vol. 2, E. Soepadmo, K. M. Wong, and L. G. Saw, Eds., pp. 192, Sabah Forestry Department, Sandakan \& Sarawak Forestry Department, FRIM, Kepong, Malaysia, 1996.

[2] K. Kochummen, "Anacardiaceae," in Tree Flora of Malaya: A Manual for Foresters, F. Ng, Ed., pp. 31-40, FRIM, Longman Malaysia, Kuala Lumpur, Malaysia, 1989.

[3] J. Bompard, "The genus Mangifera re-discovered: the potential contribution of wild species to mango cultivation," in Acta Horticulturae, pp. 69-77, 1993.

[4] I. Salma, A. Khadijah, H. Masrom, A. Azuan, M. L. Raziah, and M. A. Rahman, "Distribution and diversity of Mangifera species on farm in Malaysia," Journal of Tropical Agriculture and Food Science, vol. 38, no. 1, pp. 89-95, 2010.

[5] N. K. Rao, "Plant genetic resources: advancing conservation and use through biotechnology," African Journal of Biotechnology, vol. 3, no. 2, pp. 136-145, 2004.

[6] D. F. Marshall, "Meeting training needs in developing countries," in Molecular Genetic Techniques for Plant Genetic Resources: Report of an IPGRI Workshop, W. G. Ayad, T. Hodgkin, A. Jaradat, and V. R. Rao, Eds., pp. 128-134, IPGRI, Rome, Itlay, 1997.

[7] S. S. Pandit, S. Mitra, A. P. Giri et al., "Genetic diversity analysis of mango cultivars using inter simple sequence repeat markers," Current Science, vol. 93, no. 8, pp. 1135-1141, 2007.

[8] Thimmappaiah, W. G. Santhosh, D. Shobha, and G. S. Melwyn, "Assessment of genetic diversity in cashew germplasm using RAPD and ISSR markers," Scientia Horticulturae, vol. 120, no. 3, pp. 411-417, 2009.

[9] A. Rocha, L. C. Salomão, T. M. Salomão, C. D. Cruz, and D. L. de Siqueira, "Genetic diversity of "Uba" mango tree using ISSR markers," Molecular Biotechnology, vol. 50, no. 2, pp. 108-113, 2012.

[10] W. Eiadthong, K. Yonemori, A. Sugiura, N. Utsunomiya, and S. Subhadrabandhu, "Identification of mango cultivars of Thailand and evaluation of their genetic variation using the amplified fragments by simple sequence repeat-(SSR-) anchored primers," Scientia Horticulturae, vol. 82, no. 1-2, pp. 57-66, 1999.

[11] T. K. Behera, A. B. Gaikwad, S. Saxena, C. Bharadwaj, and A. D. Munshi, "Morphological and molecular analyses define the genetic diversity of Asian bitter gourd (Momordica charantia L.)," Australian Journal of Crop Science, vol. 6, no. 2, pp. 261-267, 2012.

[12] M. G. Murray and W. F. Thompson, "Rapid isolation of high molecular weight plant DNA," Nucleic Acids Research, vol. 8, no. 19 , pp. 4321-4326, 1980.

[13] C. E. Shannon and W. Weaver, The Mathematical Theory of Communication, 1949.

[14] I. Roldán-Ruiz, J. Dendauw, E. Van Bockstaele, A. Depicker, and M. De Loose, "AFLP markers reveal high polymorphic rates in 
ryegrasses (Lolium spp.)," Molecular Breeding, vol. 6, no. 2, pp. 125-134, 2000.

[15] J. A. Anderson, G. A. Churchill, J. E. Autrique, S. D. Tanksley, and M. E. Sorrells, "Optimizing parental selection for genetic linkage maps," Genome, vol. 36, no. 1, pp. 181-186, 1993.

[16] R. K. Varshney, K. Chabane, P. S. Hendre, R. K. Aggarwal, and A. Graner, "Comparative assessment of EST-SSR, ESTSNP and AFLP markers for evaluation of genetic diversity and conservation of genetic resources using wild, cultivated and elite barleys," Plant Science, vol. 173, no. 6, pp. 638-649, 2007.

[17] A. Prevost and M. J. Wilkinson, "A new system of comparing PCR primers applied to ISSR fingerprinting of potato cultivars," Theoretical and Applied Genetics, vol. 98, no. 1, pp. 107-112, 1999.

[18] P. H. A. Sneath and R. R. Sokal, Numerical Taxonomy: The Principles and Practice of Numerical Classification, 1973.

[19] J. F. Rohlf, "NTSYSpc, Numerical Taxonomy and Multivariate Analysis System Version 2.0 User Guide," Nat. Hist., 31, 1998, http://www.exetersoftware.com/downloads/ntsysguide.pdf.

[20] I. V. Yap and R. J. Nelson, WinBoot: A Program for Performing Bootsrap Analysis of Binary Data to Determine the Confidence Limits of UPGMA-Based Dendrograms, International Rice Research Institute, Manila, Philippines, 1996.

[21] H. P. Gajera, R. S. Tomar, S. V. Patel, R. R. Viradia, and B. A. Golakiya, "Comparison of RAPD and ISSR markers for genetic diversity analysis among different endangered Mangifera indica genotypes of Indian Gir forest region," Journal of Plant Biochemistry and Biotechnology, vol. 20, no. 2, pp. 217-223, 2011.

[22] N. Srivastava, A. Bajpai, R. Chandra, S. Rajan, M. Muthukumar, and M. K. Srivastava, "Comparison of PCR based marker systems for genetic analysis in different cultivars of mango," Journal of Environmental Biology, vol. 33, no. 2, pp. 159-166, 2012.

[23] X.-H. He, Y.-Z. Guo, Y.-M. Li, and S.-J. Ou, "Assessment of the genetic relationship and diversity of mango and its relatives by cplSSR marker," Agricultural Sciences in China, vol. 6, no. 2, pp. 137-142, 2007.

[24] N. Yamanaka, M. Hasran, D. H. Xu, H. Tsunematsu, S. Idris, and T. Ban, "Genetic relationship and diversity of four Mangifera species revealed through AFLP analysis," Genetic Resources and Crop Evolution, vol. 53, no. 5, pp. 949-954, 2006.

[25] P. Chew, M. Mahani, M. Normah, and I. Salma, "Genetic diversity and relatedness among accessions of rambutan (Nephellium lappaceum)," Malaysian Applied Biology Journal, vol. 34, pp. 21-29, 2005.

[26] B. K. Song, M. M. Clyde, R. Wickneswari, and M. N. Normah, "Genetic relatedness among Lansium domesticum accessions using RAPD markers," Annals of Botany, vol. 86, no. 2, pp. 299$307,2000$.

[27] S. Jintanawong, H. Hiranpradit, P. Duangpikul, and P. Polprasid, "Group characterization of Thai mango, Mangifera indica L.," Acta Horticulturae, no. 321, pp. 254-261, 1992.

[28] A. K. Samanta, T. K. Chattopadhyay, and S. Roy, "Genetic variability of some fruit characters in mango (Mangifera indica L.)," Environment and Ecology, vol. 17, pp. 488-490, 1999.

[29] I. Salma, T. Zahrah, and H. Masrom, "Numerical analysis of variation among Mangifera indica L. accessions," Mardi Research Journal, vol. 19, pp. 31-42, 1991.

[30] S. Singh, A. B. Gaikwad, and J. L. Karihaloo, "Morphological and molecular analysis of intracultivar variation in Indian mango (Mangifera indica L.) cultivars," Acta Horticulturae, vol. 829, pp. 205-212, 2010.
[31] R. J. Schnell, C. M. Ronning, and R. J. K. Knight Jr., "Identification of cultivars and validation of genetic relationships in Mangifera indica L. Using RAPD markers," Theoretical and Applied Genetics, vol. 90, no. 2, pp. 269-274, 1995.

[32] J. A. López-Valenzuela, O. Martínez, and O. Paredes-López, "Geographic differentiation and embryo type identification in Mangifera indica L. cultivars using RAPD markers," HortScience, vol. 32, no. 6, pp. 1105-1108, 1997.

[33] W. Eiadthong, K. Yonemori, S. Kanzaki, A. Sugiura, N. Utsunomiya, and S. Subhadrabandhu, "Amplified fragment length polymorphism analysis for studying genetic relationships among Mangifera species in Thailand," Journal of the American Society for Horticultural Science, vol. 125, no. 2, pp. 160-164, 2000.

[34] J. L. Karihaloo, Y. K. Dwivedi, S. Archak, and A. B. Gaikwad, "Analysis of genetic diversity of Indian mango cultivars using RAPD markers," Journal of Horticultural Science and Biotechnology, vol. 78, no. 3, pp. 285-289, 2003.

[35] K. V. Ravishankar, P. Chandrashekara, S. A. Sreedhara, M. R. Dinesh, L. Anand, and G. V. S. Saiprasad, "Diverse genetic bases of Indian polyembryonic and monoembryonic mango (Mangifera indica L) cultivars," Current Science, vol. 87, no. 7, pp. 870-871, 2004.

[36] E. Rivera-Ocasio, T. M. Aide, and W. O. McMillan, "Patterns of genetic diversity and biogeographical history of the tropical wetland tree, Pterocarpus officinalis (Jacq.), in the Caribbean basin," Molecular Ecology, vol. 11, no. 4, pp. 675-683, 2002. 

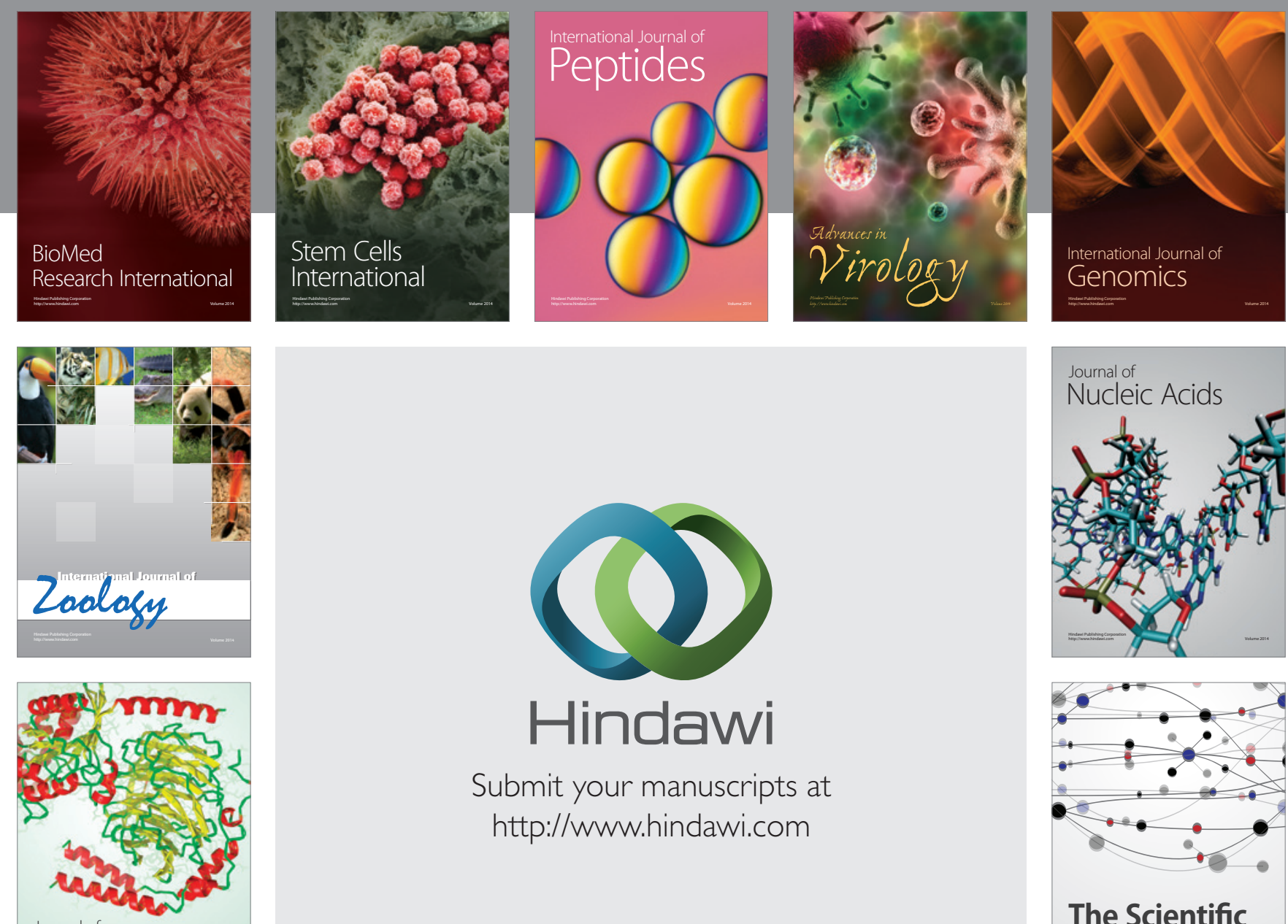

Submit your manuscripts at

http://www.hindawi.com

Journal of
Signal Transduction
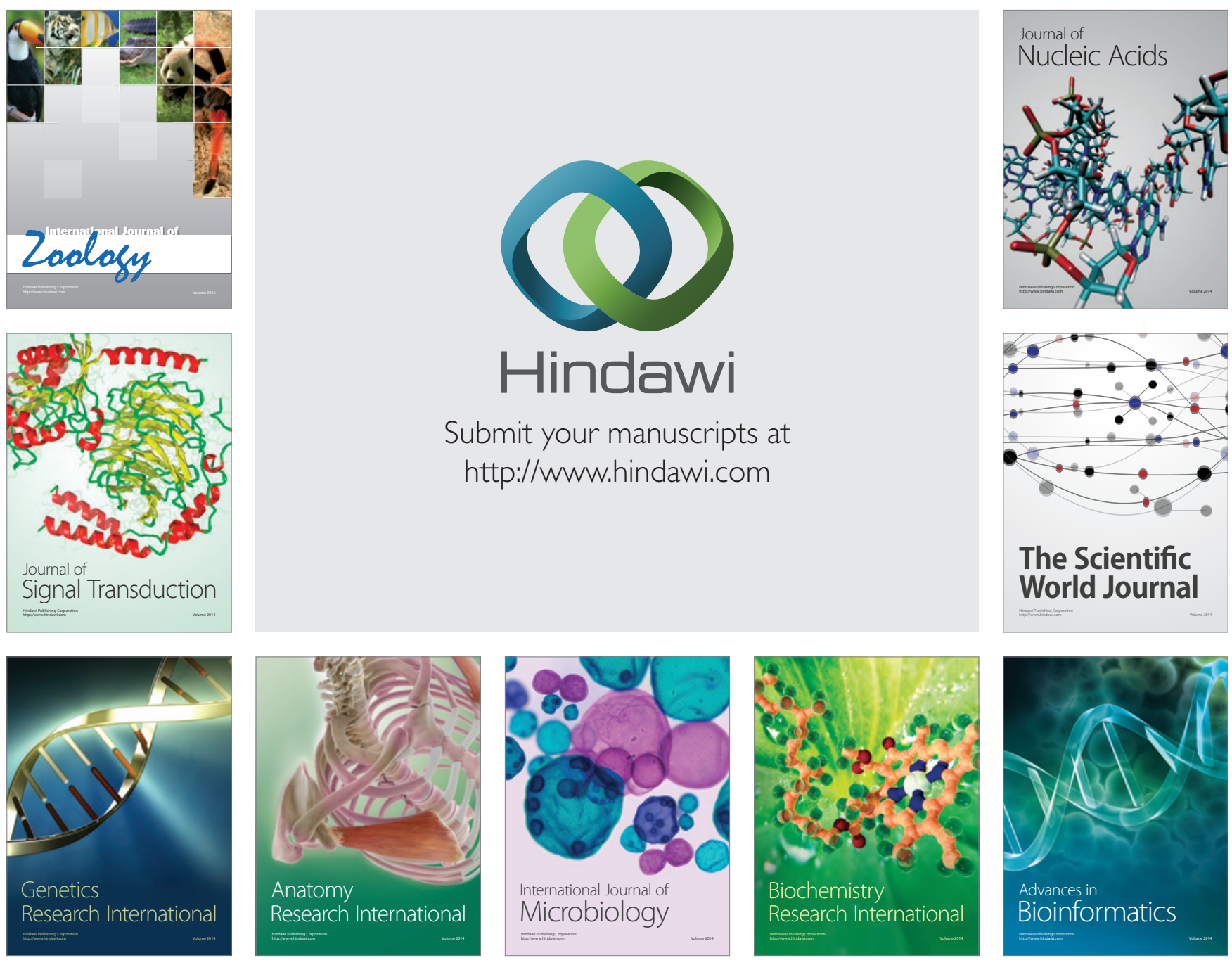

The Scientific World Journal
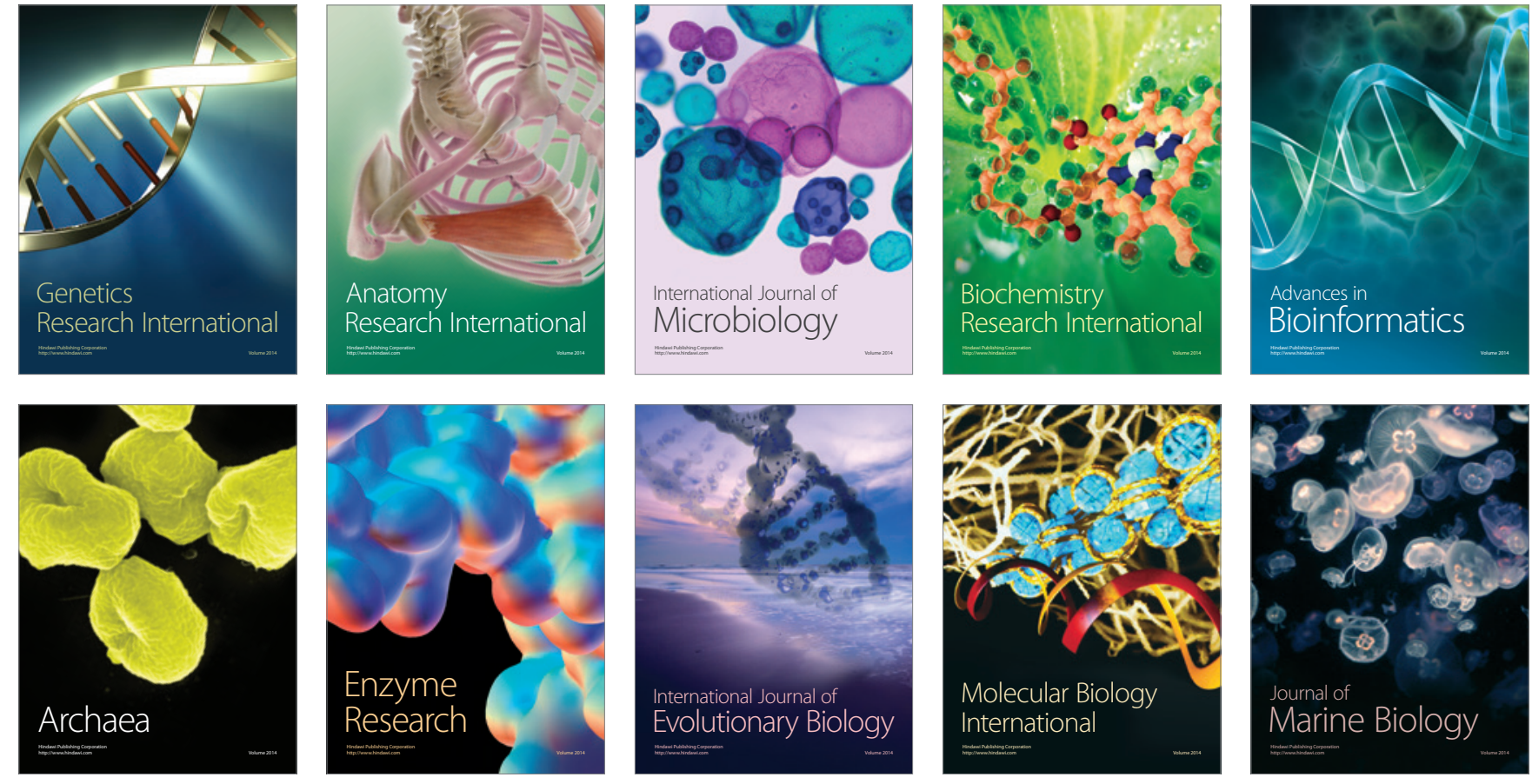